\title{
Successful Treatment of Hepatitis C Virus Infection Using Direct-Acting Antiviral Agents (DAAs) in Adolescents with Kidney Transplantation: A Case Series
}

\author{
Cahyani Gita Ambarsari (D) \\ Eka Laksmi Hidayati (D) \\ Irsan Hasan (iD) ${ }^{2}$ \\ Angela Grace (D) \\ Hanifah Oswari (D)
}

'Department of Child Health, Faculty of Medicine, Universitas Indonesia - Cipto Mangunkusumo Hospital, Jakarta, Indonesia; ${ }^{2}$ Department of Internal Medicine, Faculty of Medicine, Universitas Indonesia, Cipto Mangunkusumo Hospital, Jakarta, Indonesia

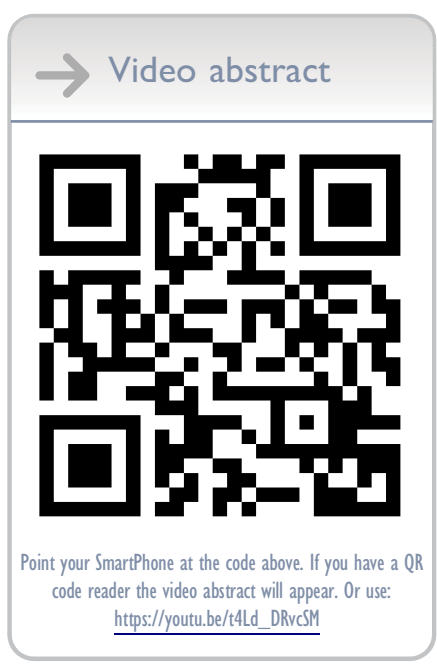

Correspondence: Cahyani Gita Ambarsari Department of Child Health, Faculty of Medicine, Universitas Indonesia, Cipto Mangunkusumo Hospital, Diponegoro 7I, Jakarta Pusat 10430, Indonesia

Tel +62 8I 2-13|4-4888

Fax +62-2I-3907743

Email cahyani.ambarsari@ui.ac.id
This article was published in the following Dove Press journal: International Journal of Nephrology and Renovascular Disease

Introduction: Hepatitis $\mathrm{C}$ virus (HCV) infection is common among end-stage renal disease patients undergoing hemodialysis. The standard treatment for $\mathrm{HCV}$ infection has been interferon-ribavirin combination prior to renal transplantation. However, compared to directacting antiviral agents (DAAs), the risk of graft rejection is higher with interferon therapy. Many recent studies have investigated the efficacy and safety of DAAs for treating HCV infection in kidney disease in adults; however, it has not been established in pediatric patients. To the best of our knowledge, this is the first report describing successful treatment using the DAAs sofosbuvir/daclatasvir in two pediatric kidney transplant recipients who had HCV genotype 1a infection without liver fibrosis.

Case Presentation: Case 1 describes a 13-year-old Indonesian boy who had undergone hemodialysis since 2014 after being diagnosed with end-stage renal disease (ESRD) secondary to bilateral renal hypoplasia. Later, he had HCV infection and was treated with interferon-based therapy with ribavirin prior to living-related renal transplantation (LRRT). The HCV was undetected and his liver function normalized six months after treatment initiation. However, 10 months after treatment initiation, he had HCV virological breakthrough, leading to cessation of interferon therapy. Plans for LRRT were continued and HCV treatment using DAAs was set up to be given post LRRT. Case 2 describes a 14-year-old Indonesian girl who also had hemodialysis prior to LRRT after she was diagnosed with ESRD secondary to nephrotic syndrome. Later, she had HCV infection and was treated with interferon and ribavirin prior to the live-unrelated renal transplantation. HCV infection did not resolve, in addition, she experienced thrombocytopeniawhich is a side effect of interferon-resulting in termination of interferon treatment. Both cases were treated with DAAs one year following renal transplantation after reaching stable graft function, leading to achievement of sustained virological response at 24 weeks.

Conclusion: Post-transplantation treatment of chronic HCV is preferred in KTRs. The sofosbuvir/daclatasvir regimen as an interferon-free therapy is a safe, effective option for $\mathrm{HCV}$ infection in pediatric KTRs, who can tolerate sofosbuvir/daclatasvir well and respond favorably without significant adverse events.

Keywords: kidney failure, chronic, interferon, renal transplantation, antiviral agents, hepatitis C

\section{Introduction}

Hepatitis $\mathrm{C}$ virus (HCV) infection is associated with significant morbidity and mortality among renal disease patients undergoing hemodialysis (HD). ${ }^{1}$ Additionally, in adult 
kidney transplant recipients (KTR), HCV infection pretransplantation increases the risk of graft failure and death. ${ }^{1}$

In 2009, Kidney Disease Improving Global Outcomes (KDIGO) recommended interferon-based therapy prerenal transplantation or DAAs post-transplantation for adult KTR with $\mathrm{HCV}^{2}$ However, recent KDIGO (2018) no longer encourages interferon-based therapy to treat $\mathrm{HCV}$ infection in chronic kidney disease (CKD). ${ }^{3}$ Moreover, direct-acting antiviral agents (DAAs) are recommended for treating chronic $\mathrm{HCV}$-infected $\mathrm{KTR}$ because of the poor efficacy and higher risk of acute allograft rejection associated with interferon-based therapy. ${ }^{4}$ However, there are limited literatures about the use of DAAs in pediatrics and clinical trials are ongoing. ${ }^{5}$

In this case series, we report achieving successful eradication-via using DAAs sofosbuvir/daclatasvir regimen-of $\mathrm{HCV}$ infection in pediatric KTR without liver fibrosis who experienced treatment failure with interferon and ribavirin prior to renal transplantation. To the best of our knowledge, this is the first report describing successful treatment using DAAs in two pediatric KTR who had HCV genotype 1a infection.

\section{Case Presentation Case I}

A 13-year-old Indonesian boy who experienced successful living-related renal transplantation (LRRT) in 2017 (his 50year-old father was his kidney donor) has been living with normal graft function. He underwent hemodialysis (HD) in 2014 after being diagnosed with end-stage renal disease (ESRD) secondary to bilateral renal hypoplasia. He was prepared for LRRT in March 2015; however, two months prior to the procedure he was infected with the hepatitis A virus (HAV). The HAV infection subsequently resolved, and LRRT preparations proceeded. Unfortunately, seven days prior to the scheduled LRRT procedure, there was a sudden significant rise in alanine transaminase (ALT) and aspartate aminotransferase (AST) levels, resulting in cancellation of the procedure. The rise in ALT and AST levels was later revealed to be caused by $\mathrm{HCV}$ seroconversion (Figure 1). The patient was always hemodialyzed with a single-use dialyzer, and there was no history of blood transfusions or family history of viral hepatitis; however, there was an HCV outbreak in our pediatric dialysis unit in 2015.

In April 2015, his liver function markers rose (AST $498 \mathrm{U} / \mathrm{L}$, ALT $816 \mathrm{U} / \mathrm{L}$, Gamma-Glutamyltransferase
(GGT) $170 \mathrm{U} / \mathrm{L}$ ) and he was subsequently diagnosed with HCV infection (viral load $3.75 \times 10^{5} \mathrm{IU} / \mathrm{mL}, 5.57$ $\log \mathrm{IU} / \mathrm{mL}$ of serum HCV RNA) (Figure 1). HCV RNA genotype testing was conducted using hybridization probe (The Versant HCV Genotype 2.0 Assay (LiPA), Siemens), which revealed HCV genotype 1a. A 7.3-kPa liver stiffness was observed with transient elastography (fibroscan), which was categorized as F1-F2 (mild-moderate liver fibrosis) (Figure 1).

$\mathrm{He}$ received interferon-based therapy with ribavirin post-HD once a week since September 2015. Six months after treatment initiation, the HCV was undetected and his liver function normalized. However, 10 months after treatment initiation, he had HCV virological breakthrough, suggested by HCV RNA of $1.28 \times 10^{4} \mathrm{IU} / \mathrm{mL}$ (4.11 Log $\mathrm{IU} / \mathrm{mL}$ ), leading to cessation of interferon therapy.

Plans for LRRT were continued and HCV treatment was set up to be given a year post LRRT when stable renal graft function was achieved. In September 2017, LRRT was conducted. One year post-LRRT, graft function was normal; thus, treatment with DAAs for chronic $\mathrm{HCV}$ infection was commenced. Owing to a lack of evidence regarding treatment safety with DAAs in pediatrics, we arranged a thorough discussion with the Hospital Ethics Committee to obtain parental consent. In December 2018, he began receiving sofosbuvir/daclatasvir for 12 weeks. Evaluation immediately after (March 2019), at 12 weeks (June 2019), and at 24 weeks (October 2019) following treatment cessation showed no HCV recurrence (Figure 1). Adverse effects, such as mild fever, fatigue, musculoskeletal pain, decreased appetite, itching and nasal congestion, were not found during treatment with DAAs.

\section{Case 2}

A 14-year-old Indonesian girl who experienced successful live-unrelated renal transplantation from a 21-year-old donor in April 2017 has been living with normal graft function. In November 2014 she was diagnosed with ESRD secondary to nephrotic syndrome and started regular HD via single-use dialyzer. She had a history of repeated blood transfusions but no family history of viral hepatitis.

She was diagnosed with $\mathrm{HCV}$ infection with a high viral load $\left(2.69 \times 10^{6} \mathrm{IU} / \mathrm{mL}, 6.43 \log \mathrm{IU} / \mathrm{mL}\right.$ of serum $\mathrm{HCV}$ RNA) and rising liver function markers (AST $180 \mathrm{U} / \mathrm{L}$, ALT 133 IU/L, GGT 142 U/L) in September 2015 (Figure 2). HCV RNA genotype testing was conducted using hybridization probe (The Versant HCV Genotype 2.0 Assay 


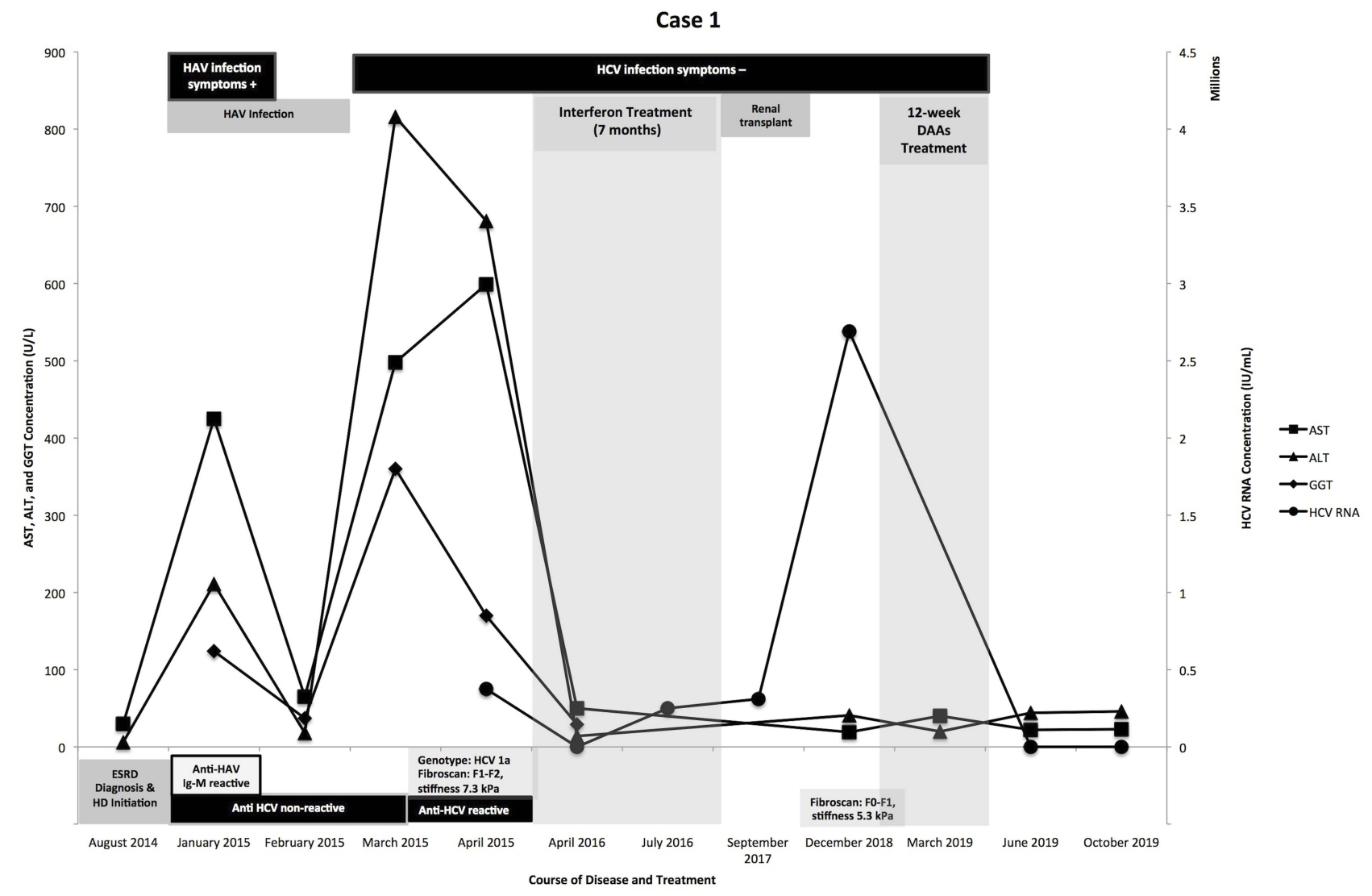

Figure I Course of disease and treatment (Case I).

(LiPA), Siemens), revealing HCV genotype 1a. A 4.8-kPa liver stiffness was observed with transient elastography (fibroscan), which was categorized as F0-F1 (mild liver fibrosis) (Figure 2).

She began receiving pegylated interferon and ribavirin in October 2015 prior to renal transplantation. Ten months later (August 2016), real-time PCR still showed the presence of HCV RNA $\left(2.56 \times 10^{6} \mathrm{IU} / \mathrm{mL}, 5.41 \mathrm{Log} \mathrm{IU} / \mathrm{mL}\right)$. In addition, she experienced thrombocytopenia - which is a side effect of interferon - resulting in termination of treatment.

In April 2017, she received kidney transplantation. At two months post-transplantation, she was diagnosed with post-transplant diabetes mellitus (PTDM), which manifested as a spontaneous inguinal abscess $(10 \times 3 \times$ $0.5 \mathrm{~cm})$, hyperglycemia $(617 \mathrm{mg} / \mathrm{dL})$, and ketonemia without acidosis. This PTDM is believed to be associated with her status as HCV-infected KTR, in addition to the side effect of tacrolimus-corticosteroid combination. PTDM resolved after tapering off methylprednisolone and seven months of insulin therapy.

At 20 months post-renal transplantation, graft function was normal; thus, treatment of $\mathrm{HCV}$ infection with DAAs was initiated. Since data about the treatment safety with DAAs in pediatrics are limited, we obtained parental consent after arranging meticulous discussion with the Hospital Ethics Committee. She started receiving sofosbuvir/daclatasvir in December 2018. HCV RNA with real-time PCR immediately after, at 12 weeks, and at 24 weeks after treatment initiation showed no HCV RNA (Figure 2). There were no adverse effects during treatment with DAAs.

\section{Discussion}

Prevalence of adult hepatitis $\mathrm{C}$ in Indonesia is $1.01 \%$ (approximately 2.6 million people) in 2017. ${ }^{6}$ However, its prevalence in children, especially children with ESRD, is unknown. In Egypt, 18\% of pediatric CKD cases had HCV infections. ${ }^{7}$ In our pediatric dialysis unit, the trend of $\mathrm{HCV}$ infection fluctuated from 0 to 5 cases among 26 to $38 \mathrm{HD}$ cases per year over the past 6 years. HD is also known as a risk factor of $\mathrm{HCV}$ infection in dialysis units; moreover, mortality among the dialysis population with $\mathrm{HCV}$ infection in Asia Pacific was higher. ${ }^{8}$ This fact is dismaying, considering that in Indonesia, the cost of HD per patient annually may reach USD $\$ 12,000$, two-fold higher than peritoneal dialysis 
Case 2

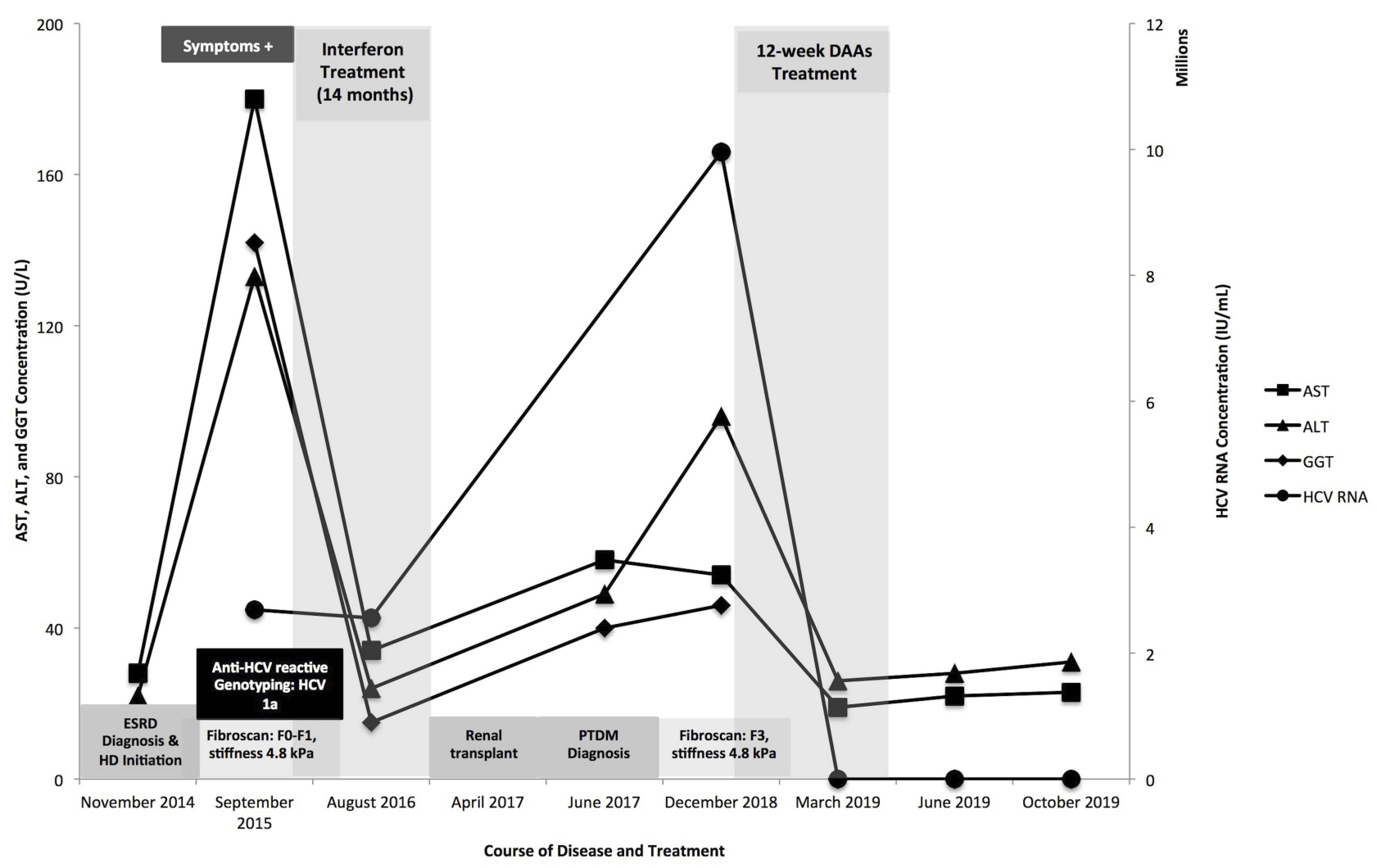

Figure 2 Course of disease and treatment (Case 2).

(PD) (USD \$6000). ${ }^{9}$ However, more patients in our setting prefer $\mathrm{HD}$ to $\mathrm{PD}$, while the seroconversion rate of $\mathrm{HCV}$ was lower in PD compared to HD. ${ }^{8}$ Nonetheless, we also have been facing challenges in PD setting due to the mechanical complications, ${ }^{9-11}$ as well as the PD-related infections, ${ }^{9,12}$ which may contribute to patients' inclination to HD. Particularly in our unit, these HCV infection cases are good examples to other dialysis patients that in HD unit, there has always a risk of developing $\mathrm{HCV}$ infection.

Adaptive and humoral immune responses in HCV infection are commonly delayed by one and two months; hence, HCV specific antibodies can only be detected starting three months after infection. However, the rise of serum transaminases secondary to the infection occurs in advance (approximately two months after initial infection). ${ }^{13}$ In our first case, there was a significant rise in serum transaminases without detected HCV antibodies, and anti-HCV was reactive in the following month. This phenomenon aligned with the natural course of HCV infection; however, it hindered our diagnosis of HCV infection.

The major goal of HCV infection treatment in KTR is to prevent viral replication after kidney transplantation. ${ }^{14}$
A recent recommendation suggests starting DAA treatment after kidney transplantation in CKD with $\mathrm{HCV}$ infection to gain 0.5 quality-adjusted live years and to save more than $\$ 40,000$ over the remaining life span of a KTR. ${ }^{15}$ Compared to interferon-based therapy, DAAs for HCV infection in KTR has better efficacy and tolerability post-transplantation. ${ }^{16}$ Side effects of interferon-based therapy include hematological disorder, which is consistent with case 2 in our report who had thrombocytopenia as a side effect of interferon and ribavirin therapy. ${ }^{17}$ Minor adverse events such as mild fever, fatigue, musculoskeletal pain, decreased appetite, itching and nasal congestion were reported in cases of previous use of DAAs in adolescents. ${ }^{18}$ Other adverse events in adults were tinnitus, diarrhea, elevation in serum creatinine, abdominal pain, and unstable blood pressure. No such events were noted in our cases.

In Indonesia, less than $1 \%$ of the $\mathrm{HCV}$-infected population was treated with DAAs. ${ }^{19}$ Recently, FDA approved DAAs (sofosbuvir/ledipasvir) use for children, who are 12 years old or older and weigh at least $35 \mathrm{~kg}$, to treat $\mathrm{HCV}$ genotypes 1, 4, 5 and 6 infections. ${ }^{5}$ Because of the unavailability of sofosbuvir/ledipasvir (HarvoniC) in Indonesia, we 
used sofosbuvir/daclatasvir regimen, which is being supported by the government. Use of Harvoni $\odot$ in our country would require importing the regimen from abroad. It would also be costly, because patients have to independently fund the medications. This situation is sometimes found in our country; as a developing country, we found constraints in resources to provide the standardized medical service. Previously, there were publications from Indonesia describing a similar challenge due to the unavailability of supporting laboratories, ${ }^{20-22}$ which could require specimen transfer to laboratories outside the country and necessitated out-ofpocket expenses. As a matter of fact, the gross domestic product per capita of Indonesia in 2018 was USD \$3893.60, while the cost of Harvonic is USD \$94,500 for a 12-week-treatment (in America). ${ }^{23,24}$ Therefore, sofosbuvir/daclatasvir regimen was preferred for the benefit of the patients. Sofosbuvir/daclatasvir as regimen of choice for $\mathrm{HCV}$-infected KTR is efficient and safe in adults; however, only partial results of two pediatric trials involving chronic $\mathrm{HCV}$ infection population have been reported to date. ${ }^{5,25}$ Additionally, a recent study in Egypt revealed that there were no differences in efficacy and safety between the use of sofosbuvir/ledipasvir and sofosbuvir/daclatasvir in adolescents with HCV non-KTR without other comorbidities. ${ }^{26}$ In their study, all of the subjects achieved SVR12 regardless of the treatment regimen, which justified our decision to use sofosbuvir/daclatasvir regimen in our patients.

Tacrolimus target levels post-transplantation in pediatric KTR were 10-12 ng/mL (month one), $8-10 \mathrm{ng} / \mathrm{mL}$ (months two to three), 6-8 $\mathrm{ng} / \mathrm{mL}$ (months four to six) and 4-6 ng/mL (after month six). ${ }^{27}$ Therefore, we monitored tacrolimus levels accordingly after transplantation and particularly during administration of DAAs (Figure 1). The first tacrolimus measurements within a month post-DAAs initiation in our cases showed elevation past the target level (Figure 3). Moreover, there was a significant increase in serum creatinine level in case 1 (Figure 3A), raising a suspicion that DAAs may potentiate tacrolimus nephrotoxicity. A 2017 review stated that the incidence of nephrotoxicity is higher in patients receiving a medium-dose regimen of tacrolimus $(0.15 \mathrm{mg} / \mathrm{kgBW} /$ day $)$ compared to a low-dose regimen $(0.1 \mathrm{mg} / \mathrm{kgBW} /$ day $){ }^{28}$ This explains the rise of serum creatinine in case 1 (Figure $3 \mathrm{~A}$ ) compared to the stability of serum creatinine in case 2 (Figure 3B). Older donor age in kidney transplantation also contributes to the nephrotoxicity side effects of tacrolimus, ${ }^{29}$ thus aligning with the fact that case 1 received kidney from his 50year-old father, whereas the donor for case 2 was 21 years old. Therefore, the tacrolimus dose was reduced to maintain a level within the desired target for both cases, and also to preserve graft function particularly for case 1. However, when DAAs were discontinued, the tacrolimus levels dropped in both cases, necessitating an increased dose of tacrolimus.

Tacrolimus is a substrate of liver cytochrome (CYP) $3 \mathrm{~A} 4$, which is commonly repressed during chronic $\mathrm{HCV}$ infection by the inflammatory cytokines. ${ }^{30}$ Treatment with DAAs overrides the inflammatory inhibition of CYP3A4 and enhances tacrolimus metabolism, leading to decreased concentration and eventually requiring an increase in tacrolimus dose. ${ }^{4,30}$ In our cases, tacrolimus levels rose during DAAs treatment. Only one study in 2016 reported an increase of tacrolimus levels and serum creatinine levels during DAAs treatment in 13 out of 47 subjects. ${ }^{4}$ A recent pharmacology study in 2018 suggested that the bioavailability of tacrolimus administered in Asians is greater, ${ }^{31}$ implying that the tacrolimus dose requirement may be lower generally in our cases and required adjustment while on DAAs.

Case 1 exhibited a timely course of HCV infection and that the first measurement of anti-HCV was non-reactive. This hindered the diagnosis of HCV. Moreover, hepatitis A infection occurred prior to HCV infection, and LRRT added the unique feature of this case. Another hallmark of this case series is the PTDM phenomenon that occurred in case 2. HCV-infected KTR patients are known to have an increased risk of developing PTDM, particularly those who receive tacrolimus and corticosteroid post-transplantation. ${ }^{32}$ Inhibitory actions on the insulin regulatory pathways of the liver by HCV lead to insulin resistance and eventually result in PTDM. ${ }^{32}$

Ultimately, both cases achieved sustained virological response (SVR) at 24 weeks (SVR24), indicating that treatment for HCV infection using DAAs is effective and well tolerated in post-transplantation patients, particularly in the pediatric population. This is similar to a 2016 study in China, which revealed successful treatment using sofosbuvir/daclatasvir in adult HCV-infected KTR genotype 1 without liver involvement, achieving SVR at 12 weeks. ${ }^{25}$ In addition, sofosbuvir/daclatasvir combination has recently been reported as effective and safe to treat chronic HCV genotype 4 infection without other comorbidities in children aged 8 to 18 years old. ${ }^{18}$ To the best of our knowledge, this is the first report describing successful treatment using DAAs in two pediatric KTR who had HCV genotype 1a infection. 


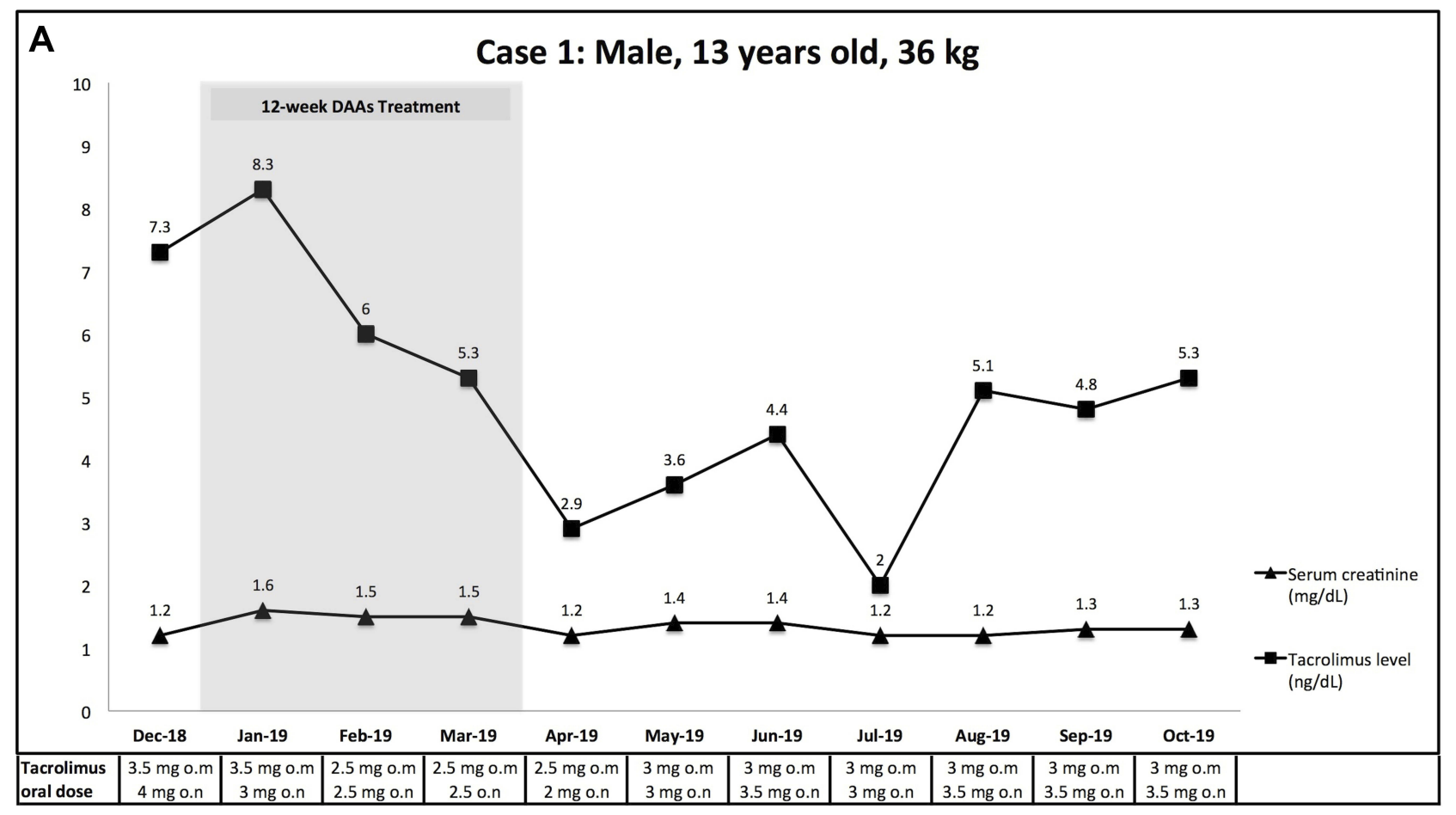

\section{B}

Case 2: Female, 14 years old, $34 \mathrm{~kg}$

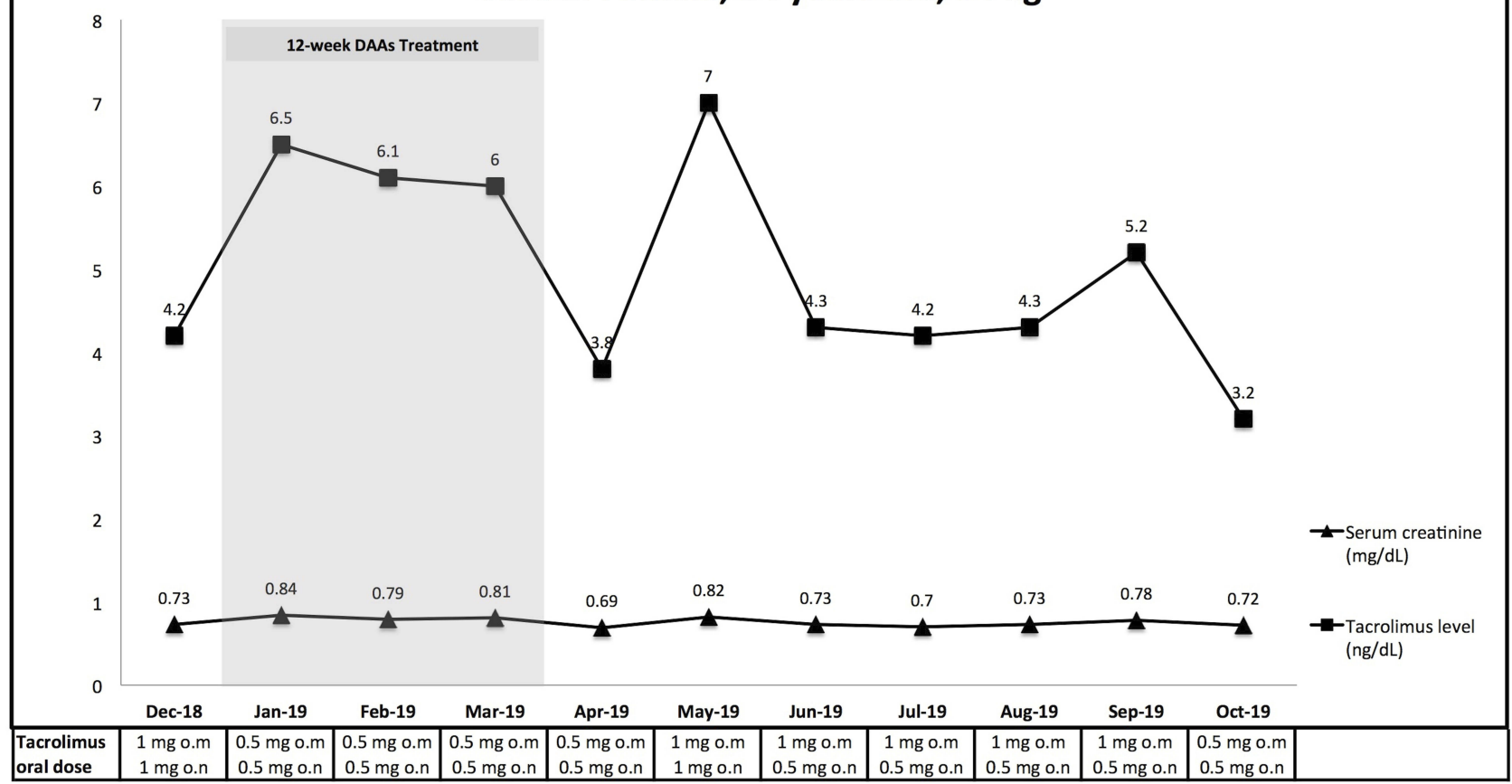

Figure 3 (A) Tacrolimus and creatinine serum levels changes while on treatment with DAAs (Case I). (B) Tacrolimus and creatinine serum levels changes while on treatment with DAAs (Case I).

\section{Conclusion}

Sofosbuvir/daclatasvir, preferably administered posttransplantation, is a safe and effective interferon-free treatment option in chronic HCV-infected pediatric KTRs.
Further studies are warranted to confirm the efficacy and safety of DAAs in pediatric KTRs with chronic HCV infection, and to elucidate the effects of DAAs on tacrolimus levels and nephrotoxicity. 


\section{Ethical Statements}

In both cases, the organs were donated voluntarily with written informed consent, and the transplantations were conducted in accordance with the Declaration of Istanbul. Written informed consent for the publication of this case series and accompanying images was obtained from the patients' guardian. A copy of the written consent is available for review from the editor of this journal. Further institutional approval is not required to publish de-identified case information.

\section{Acknowledgments}

We would like to express our gratitude to Professor Taralan Tambunan, Professor Partini Pudjiastuti Trihono, Sudung Oloan Pardede, MD, PhD and Henny Adriani Puspitasari, MD for their care of the patients in the Department of Child Health; Professor Mei-Hwei Chang from Department of Pediatrics, National Taiwan University Hospital, Taipei, Taiwan for providing guidance in therapy; Farhan Haidar Fazlur Rahman, MD and Tiara Nien Paramita, MD for the assistance in data recruitment; and ENAGO for the careful reading and editing of this manuscript.

\section{Author Contributions}

All authors contributed to data analysis, drafting or revising the article, gave final approval of the version to be published, and agree to be accountable for all aspects of the work.

\section{Disclosure}

The authors report no conflicts of interest in this work.

\section{References}

1. Dzekova-Vidimliski P, Sikole A. Hepatitis C virus infection in kidney transplant patients: current treatment options. Exp Clin Transplant. 2017; 15:587-593.

2. Kidney Disease: Improving Global Outcomes Transplant Work Group. KDIGO clinical practice guideline for the care of kidney transplant recipients. Am J Transplant. 2009;9:S1.

3. Kidney Disease: Improving Global Outcomes Hepatitis C Work Group. KDIGO 2018 clinical practice guideline for the prevention, diagnosis, evaluation, and treatment of hepatitis $\mathrm{C}$ in chronic kidney disease. Kidney Int Suppl. 2018;8(3):91. doi:10.1016/j.kisu.2018.06.001

4. Fernández I, Muñoz-Gómez R, Pascasio JM, et al. Efficacy and tolerability of interferon-free antiviral therapy in kidney transplant recipients with chronic hepatitis C. J Hepatol. 2017;13(4):1225. doi:10.1016/j.jhep.2016.12.020

5. Indolfi G, Thorne C, El Sayed MH, Giaquinto C, Gonzalez-Peralta RP. The challenge of treating children with hepatitis $\mathrm{C}$ virus infection. J Pediatr Gastroenterol Nutr. 2017;64(6):851-854. doi:10.1097/ MPG.0000000000001589

6. Kementerian Kesehatan Republik Indonesia. 150 ribu orang potensial alami hepatitis kronis; 2017. Available from: https://www.kemkes.go. $\mathrm{id} /$ article/view/17072800006/150-ribu-orang-potensial-alami-hepatitiskronis.html. Accessed October 23, 2019.
7. Youssef DM, Abdo H, Alakhras A, Adham T, Mohamoud AH. Hepatitis C in children with chronic kidney disease: a single-center, Egypt. Saudi J Kidney Dis Transpl. 2017;28:102. doi:10.4103/13192442.198161

8. Johnson DW, Dent H, Yao Q, et al. Frequencies of hepatitis B and $\mathrm{C}$ infections among haemodialysis and peritoneal dialysis patients in Asia-Pacific countries: analysis of registry data. Nephrol Dial Transplant. 2008;24:1598-1603. doi:10.1093/ndt/gfn684

9. Ambarsari CG, Trihono PP, Kadaristiana A, et al. Five-year experience of continuous ambulatory peritoneal dialysis in children: a single center experience in a developing country. Med J Indones. 2019;28(4):329-337. doi:10.13181/mji.v28i4.3807

10. Ambarsari CG, Bermanshah EK, Putra MA, Rahman FHF, Pardede SO. Effective management of peritoneal dialysis-associated hydrothorax in a child: a case report. Case Rep Nephrol Dial. 2020;10(1):18-25. doi:10.1159/000506119

11. Ambarsari CG, Rahman FHF, Bermanshah EK, Kadaristiana A. An unusual case of peritoneal dialysis twisted catheter in a child. $J$ Indones Med Assoc. 2020;70(2):27-31.

12. Ambarsari CG, Mushahar L, Kadaristiana A, Hidayati EL. Dressing versus non-dressing technique for exit-site care in children on chronic ambulatory peritoneal dialysis: a pilot retrospective cohort. Med J Indones. 2020

13. Rehermann B, Nascimbeni M. Immunology of hepatitis B virus and hepatitis $\mathrm{C}$ virus infection. Nat Rev Immunol. 2005;5(3):215. doi:10.1038/nri1573

14. Gutierrez JA, Lawitz EJ, Poordad F. Interferon free, direct acting antiviral therapy for chronic hepatitis C. J Viral Hepat. 2015;22 (11):861-870. doi:10.1111/jvh.12422

15. Wong G, Coates T. To transplant early or treat first? A dilemma for hepatitis C-positive recipients. Kidney Int. 2019;96(3):535-539. doi:10.1016/j.kint.2019.02.024

16. Kwo PY, Badshah MB. New hepatitis $C$ virus therapies: drug classes and metabolism, drug interactions relevant in the transplant settings, drug options in decompensated cirrhosis, and drug options in end-stage renal disease. Curr Opin Organ Transplant. 2015;20 (3):235-241. doi:10.1097/MOT.0000000000000198

17. Chopra A, Klein PL, Drinnan T, Lee SS. How to optimize HCV therapy in genotype 1 patients: management of side effects. Liver Int 2013;33:30-34. doi:10.1111/liv.12080

18. Abdel Ghaffar TY, El Naghi S, Abdel Gawad M, et al. Safety and efficacy of combined sofosbuvir/daclatasvir treatment of children and adolescents with chronic hepatitis C genotype 4. J Viral Hepat. 2019;26(2):263-270. doi:10.1111/jvh.13032

19. Hill AM, Nath S, Simmons B. The road to elimination of hepatitis C: analysis of cures versus new infections in 91 countries. J Virus Erad. 2017;3(4):117.

20. Ambarsari CG, Sindih RM, Saraswati M, Trihono PP. Delayed admission and management of pediatric acute kidney injury and multiple organ dysfunction syndrome in children with multiple wasp stings: a case series. Case Rep Nephrol Dial. 2019;9 (3):137-148. doi:10.1159/000504043

21. Ambarsari CG, Cahyadi D, Sari L, et al. Late diagnosis of LeschNyhan disease complicated with end-stage renal disease and tophi burst: a case report. Ren Fail. 2020;42(1):113-121. doi:10.1080/ 0886022X.2020.1713805

22. Ambarsari CG, Trihono PP, Kadaristiana A, et al. Low-dose maintenance intravenous iron therapy can prevent anemia in children with end-stage renal disease undergoing chronic hemodialysis. Int J Nephrol. 2020.

23. GDP per capita (current US\$). 2018. Available from: https://data. worldbank.org/indicator/ny.gdp.pcap.cd. Accessed November 11, 2019

24. Rachel Nall R. How much does hepatitis C treatment cost? 2018. Available from: https://www.medicalnewstoday.com/articles/323767. php-drug-types-and-costs. Accessed November 11, 2019. 
25. Xue Y, Zhang L-X, Wang L, Li T, Qu Y-D, Liu F. Efficacy and safety of sofosbuvir and daclatasvir in treatment of kidney transplantation recipients with hepatitis $\mathrm{C}$ virus infection. World $J$ Gastroenterol. 2017;23(32):5969. doi:10.3748/wjg.v23.i32.5969

26. Hanno AH, Hamouda S, Abdelgawad M, Aboelkheir H, Ahmed M. Comparison between safety and efficacy of two treatment regimens for pediatric patients with chronic hepatitis $\mathrm{C}$ virus infection: sofosbuvir/ledipasvir versus sofosbuvir/daclatasvir regimen. Acta Sci GI Disord. 2019;2(7):3-7. doi:10.31080/ASGIS.2019.02.0069

27. Transplant BC. Clinical guidelines for transplant medications. Vol AMB.03.007 Rev11: British Columbia Transplant; 2019. Available from: http://www.transplant.bc.ca/Documents/HealthProfessionals/ Clinicalguidelines/ClinicalGuidelinesforTRANSPLANTMEDIC ATIONS.pdf.

28. Andrews LM, Li Y, De Winter BCM, et al. Pharmacokinetic considerations related to therapeutic drug monitoring of tacrolimus in kidney transplant patients. Expert Opin Drug Metab Toxicol. 2017;13 (12):1225-1236. doi:10.1080/17425255.2017.1395413
29. Xia T, Zhu S, Wen Y, et al. Risk factors for calcineurin inhibitor nephrotoxicity after renal transplantation: a systematic review and meta-analysis. Drug Des Dev Ther. 2018;12:417. doi:10.2147/DDDT. S149340

30. Fernández-Ruiz M, Polanco N, García-Santiago A, et al. Impact of anti-HCV direct antiviral agents on graft function and immunosuppressive drug levels in kidney transplant recipients: a call to attention in the mid term follow up in a single center cohort study. Transpl Int. 2018;31(8):887-899. doi:10.1111/tri.13118

31. Lu Z, Bonate P, Keirns J. Population pharmacokinetics of immediateand prolonged-release tacrolimus formulations in liver, kidney and heart transplant recipients. Br J Clin Pharmacol. 2019;85(8):16 92-1703. doi:10.1111/bcp.13952

32. Palepu S, Prasad GVR. New-onset diabetes mellitus after kidney transplantation: current status and future directions. World J Diabetes. 2015;6(3):445. doi:10.4239/wjd.v6.i3.445

\section{Publish your work in this journal}

The International Journal of Nephrology and Renovascular Disease is an international, peer-reviewed open-access journal focusing on the pathophysiology of the kidney and vascular supply. Epidemiology, screening, diagnosis, and treatment interventions are covered as well as basic

science, biochemical and immunological studies. The manuscript management system is completely online and includes a very quick and fair peer-review system, which is all easy to use. Visit http://www.dovepress.com/testimonials.php to read real quotes from published authors. 